Copyright (C) 2021 by Cherkas Global University

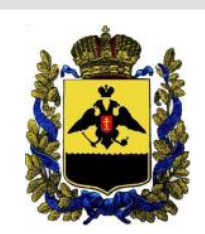

Published in the USA

Bylye Gody

Has been issued since 2006.

E-ISSN: $2310-0028$

2021. 16(4): 1710-1715

DOI: $10.13187 /$ bg.2021.4.1710

Journal homepage:

https://bg.cherkasgu.press

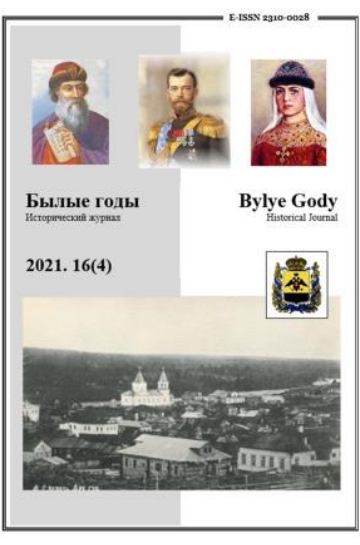

\title{
To the Question of the Spread of Plague in Circassia in the first half of the 19th century
}

Timur A. Magsumov a, b, c, * , Teymur E. Zulfugarzade d, Mikhail B. Kolotkov e, Sergei B. Zinkovskii f

a Cherkas Global University, Washington, USA

b Volgograd State University, Volgograd, Russian Federation

c Naberezhnye Chelny State Pedagogical University, Naberezhnye Chelny, Russian Federation

${ }^{d}$ Russian Economic University named after G.V. Plekhanov, Moscow, Russian Federation

e Peter the Great St. Petersburg Polytechnic University, St.Petersburg, Russian Federation

f Peoples' Friendship University of Russia (RUDN University), Moscow, Russian Federation

\section{Abstract}

The work considers the sanitary and epidemiological state of Circassia in the first half of the XIX century. The attention is paid to the causes of plague outbreaks in the region, as well as the factors that ensure its spread.

There were used as sources the documents of the regional archive - the State Archive of the Krasnodar Krai (Krasnodar, Russian Federation), which were introduced into scientific circulation for the first time. The documents of 5 funds were used in the work: Fund 249 "Office of the command (military) ataman of the Kuban Cossack army, Yekaterinodar, Kuban region, 1787-1917"; Fund 250 "Military Office of the Black Sea Cossack army, Yekaterinodar, 1794-1842"; Fund 324 "Yekaterinodar private quarantine, Yekaterinodar, 18011861"; Fund 329 "Yekaterinodar exchange yard of the Black Sea Cossack army, Yekaterinodar, 1830-1846"; Fund 687 "Ust-Labinsk barter yard of the chief trustee of Caucasian barter relations with the Highlanders".

The principle of historicism is of great importance in the work, thanks to which the outbreaks of plague on the territory of Circassia were considered in the context of the current historical situation throughout the Caucasus. In the course of the work, general scientific methods were also used: logical, classification, factor analysis, etc., as well as such special research methods as comparative, statistical and typological. During the work, the general scientific methods were also used: logical, classific, factor analysis, etc., as well as such special research methods as comparative, statistical and typological.

In conclusion, the authors state that outbreaks of plague on the territory of Circassia were not uncommon, they were recorded in 1796, 1801-1802, 1820, 1822-1823, 1830, and 1835-1836. Both in Georgia and in Circassia, the population's protective reaction to the outbreak of the plague was flight from the epidemic area, which contributed to the spread of the plague to new areas not yet covered by it. It was possible to minimize the risk of infection with the plague of the region in Circassia only by quarantine measures on the Black Sea coast for all visitors. However, it was impossible to do it at that stage of development of Circassian society due to its decentralization, as well as a high degree of dependence on trade with the Ottoman Empire.

Keywords: plague, Circassia, the Caucasus, the first half of the 19th century, the Russian Empire, quarantines, exchange yards, the Ottoman Empire, the highlanders.

\section{1. Введение}

Проблема инфекционных заболеваний на Кавказе в XIII-XIX веках стояла достаточно остро. Причинами этому были как оживленные торговые связи, так и ведение боевых действий различными противоборствующими сторонами. Скученность большого количества людей,

\footnotetext{
${ }^{*}$ Corresponding author

E-mail addresses: nabonid1@yandex.ru (T.A. Magsumov)
} 
антисанитария, а также передвижение источников заболевания по торговым путям на большие расстояния приводили к быстрому распространению болезней и созданию условий для возникновения эпидемий. В данной работе мы хотели бы рассмотреть вспышки чумы на территории Черкесии в первой половине XIX века.

\section{2. Материалы и методы}

В качестве источников привлечены документы государственного архива Краснодарского края (Краснодар, Российская Федерация), которые впервые введены в научный оборот. В работе были использованы документы 5 фондов: 249 «Канцелярия наказного (войскового) атамана Кубанского казачьего войска, г. Екатеринодар Кубанской области, 1787-1917 гг.»; 250 «Войсковая канцелярия Черноморского казачьего войска, г. Екатеринодар, 1794-1842 гг.»; 324 «Екатеринодарский частный карантин, г. Екатеринодар, 1801-1861 гг.»; 329 «Екатеринодарский меновой двор Черноморского казачьего войска, г. Екатеринодар, 1830-1846 гг.»; 687 «Усть-Лабинский меновый двор главного попечителя кавказских меновых сношений с горцами».

Важное значение в работе имеет принцип историзма, благодаря которому были рассмотрены вспышки чумы на территории Черкесии в контексте сложившейся исторической обстановки на всем Кавказе. В ходе работы применялись также общенаучные методы: логический, классификационный, метод факторного анализа и др., а также такие специальные методы исследования, как сравнительный, статистический и типологический.

\section{3. Обсуждение}

Тема распространения инфекционных заболеваний на Кавказе в дореволюционный период, благодаря введению в научный оборот новых архивных документов, в последние годы активно обсуждается. Большая работа по изучению различных аспектов медико-санитарного дела на территории Кавказа была проведена исследовательской группой И.А. Ермачкова. Так, авторы обращались к изучению санитарно-эпидемиологической деятельности русской армии на Кавказе в конце XVIII - начале XIX вв. (Ermachkov et al., 2017), рассматривалась также традиционная грузинская медицина и борьба ее со вспышками чумы в начале XIX в. (Ermachkov et al., 2017a), а также военно-санитарное дело на Кавказе в начале XIX века (Ermachkov et al., 2017b). Отдельно авторы обратились к теме «Чума на Кавказе в 18011815 гг.», где в большинстве случаев затрагивалась территория Грузии (Ermachkov et al., 2018; Ermachkov et al., 2018a). Не обошли они вниманием и тему роли генерала Ермолова в эволюции санитарного дела на Кавказе (Ermachkov et al., 2018b), а также обратили внимание на особенности санитарной обстановки в условиях русско-персидской войны 1826-1828 гг. (Ermachkov et al., 2018c).

Вопросы распространения чумы в период русско-турецких и русско-персидских войн нашли отражение в трудах А.А. Черкасова с авторским коллективом (Cherkasov et al., 2017; Cherkasov et al., $2017 \mathrm{a})$. Делались попытки анализа эпидемий чумы на Северном Кавказе и другими учеными. Так, например, авторский коллектив с Е.С. Котеневым рассматривал историю этого явления (Котенев и др., 2016).

Из краткого историографического обзора видно, что в большинстве случаев при изучении темы инфекционных заболеваний рассматривались территории Грузии, Дагестана, Кабарды. В свою очередь исследователи редко обращались к изучению этого явления на черноморском побережье и на территории Черкесии. Мы постараемся восполнить этот пробел.

\section{4. Результаты}

Как известно, в 1792 г. на российско-черкесской границе по реке Кубань появились черноморские казаки. Практически с первых дней своего расселения на этой территории казаки занимались и созданием условий для борьбы с инфекционными заболеваниями. Дело в том, что уже в 1796 г. в Черкесии была зафиксирована крупная вспышка заболевания чумой (Туренко, 1887: 41). Для этой цели по всей границе с черкесами создавались специальные карантины, где все въезжающие в Россию обязаны были находиться в течение 14 дней. Помимо этого, русская администрация собирала информацию об эпидемиологической обстановке на территории Черкесии.

Одна из первых вспышек заболевания в Черкесии в XIX веке произошла уже в 1801 г., она была характерна для всей территории Кавказа, а ее эпицентром стала Османская империя, откуда собственно ее и завезли на Кавказ (Ermachkov et al., 2018: 121). Интересно отметить, что когда в Грузии возникала вспышка чумы до прихода русских на Кавказ, то население разбегалось, кто куда хотел (Ermachkov et al., 2018: 122), тем самым создавались условия для распространения чумы.

12 декабря 1801 г. чиновник Бугазской карантинной конторы Линтварев доносил в канцелярию Черноморского войска в Екатеринодар, что прибывший на карантин анапский житель еврей Берко Исакович утверждал о наличии в Анапе заразительной болезни, от которой, по его словам, заболевшие умирали на второй-третий день по два и более человек ежедневно. Эта болезнь была завезена турецкими янычарами из Трапезунда, где в то время она сильно свирепствовала. О наличии данной болезни в горах у черкесов сведений не было, но было известно, что черкесы воздерживались от поездок в Анап (ГАКК. Ф. 250. Оп. 2. Д. 24. Л. 1-10б.). Своим сообщением Линтварев предостерегал администрацию войска и карантинные заставы о возможной опасности. 
Важно пояснить, что получение таких сигналов перепроверялось при ближайшей возможности, для чего активно использовались мирные горцы. Так уже через 6 дней на этот же карантин прибыл ногайский мурза Бахтигирей, который проживал в закубанской деревне Адалы. Он подтвердил, что в Анапе свирепствует моровая язва (она же чума - Авт.), в связи с чем ни ногайцы из Адалы, ни горские черкесы в Анап не ездят. Мурза подтвердил, что болезнь была завезена янычарами из Трапезунда (ГАКК. Ф. 25О. ОП. 2. Д. 24. Л. 20-200б.).

30 декабря 1801 г. чиновник Екатеринодарского менового двора Константинов доносил, что прибывший в этот день закубанский житель деревни Тычмирз черкес Тлимаф объявил, что слышал с неделю назад, что в Анапе усиливается заразная болезнь и что она уже появилась на хуторе черкеса Фужело Мефоатх, который находился в 20 верстах от Анапы, и от этой болезни вся семья из пяти человек вымерла. О других случаях заболевания у черкесов Тлимаф ничего не слышал (ГАКК. Ф. 250. Оп. 2. Д. 24. Л. 25-250б.).

Спустя два месяца, 21 февраля 1802 г. Константинов сообщил канцелярии Черноморского казачьего войска, что прибывший закубанский черкесский дворянин Начу Шеретлук Оглу сообщил, что, согласно его сведениям, в Анапе опасная заразительная болезнь продолжает свирепствовать и что эта болезнь уже распространилась по черкесским аулам в 30 верстах от Анапа по реке Шим (ГАКК. Ф. 25О. ОП. 2. Д. 24. Л. 46).

Уже 26 февраля появились сведения о распространении чумы и новых жертвах от болезни у черкесов. Так, 26 февраля Константинов получил сведения от нахичеванского мещанина Александра Хачадурова, который торговал за Кубанью, о том, что в черкесском селении Нарткач, в 60 верстах от Анапа, свирепствует заразительная болезнь, от которой за одну неделю из 5 дворов вымерло 30 человек. При этом источник сообщил, что заразились эти люди от выменянного ими из Анапы товара. Хачадуров также сообщил, что о болезни в других черкесских селениях он ничего не слышал (ГАКК. Ф. 250. ОП. 2. Д. 24. Л. 53).

Чума продолжала свирепствовать в Черкесии всю весну и лето. Так, 28 июля 1802 г. Константинов в своем рапорте в Черноморскую войсковую канцелярию сообщал, что приехавший 26 июля от подполковника Султана Алли Шеретлуга оглу его родной брат Начу объявил, что во владении шапсугов на реках Боундуре, Абин и Шип между жителями была опасная заразная болезнь, от которой две недели назад до 5 дворов людей вымерло (ГАКК. Ф. 250. Оп. 2. Д. 24. Л. 184). В августе болезнь пошла на спад, а в сентябре-октябре сведения о чуме из Черкесии перестали поступать.

Таким образом, чума просуществовала в Черкесии в период с начала декабря 1801 г. по август 1802 г. Однако на территории Грузии, Кабарды, Дагестана эпидемия продолжалась вплоть до 1804 г., и только потом количество зараженных стало сокращаться. О масштабах этой эпидемии в некоторых районах Кавказа имеются такие сведения: население Кабарды во время эпидемии сократилось на 80 \% (Ermachkov et al., 2018: 128).

Все случаи поступления информации о заразных болезнях у черкесов будут тщательно проверяться и держаться на контроле и в последующее время. Так, командир казачьего полка майор Дыдымов 5 августа 1820 г. писал в Усть-Лабинский карантин и меновый двор, что «торгующий в УстьЛабинской станице армянин Осип Хиндамов сего августа 4-го числа объявил мне, что якобы на речке Лабе во владении Мисоуста бек Айтекова в двух аулах, первом Цугус Хабле, где живут армяне, расстоянием от крепости Усть-Лабинской в 5-ти верстах, а во втором Чамо Хабле узденина Чора в 20-ти верстах существует на людях заразительная болезнь, почему благоволит оный карантин и меновой двор обстоятельно узнать, что действительно ли имеется в помянутых аулах заразительная болезнь, то с какого месяца и числа открылась, сколько померло и сколько находится больных или такой не имеется в самоскорейшем времени обстоятельно с сим нарочным меня уведомить для донесения... От какой прошу взять должную предосторожность...» (ГАКК. Ф. 687. Оп. 1. Д. 12. Л. 20-20об.).

Летом 1822 г. вспышка чумы была зафиксирована у натухайцев. Так, в начале июня 1822 г. командир Навагинского пехотного полка подполковник Урнежевский доносил в канцелярию войска, что в натухайском владении у реки Пшишь, в деревне Султановой и Бураны, около двух недель назад началась заразительная болезнь и несколько человек от этой болезни умерло (ГАКК. Ф. 324. Оп. 1. Д. 30. Л. 490б.-50). В непосредственной близости от русской границы по рекам Лаба и Белая, в ауле Хатузука, вымерло 13 семей, а в ауле Каплан Чирея - 20 семейств. Пытаясь спастись от чумы, население, бросив свои жилища, стало скрываться в лесах и каждое утро до восхода солнца купалось в реке Кубань и купало собственный скот. После подтверждения этой информации по всей Кордонной линии были усилены меры предосторожности, а все меновые дворы были закрыты (ГАКК. Ф. 324. Оп. 1. Д. 30. Л. 57об.-58об.). Иными словами, как в Грузии, так и в Черкесии для поведения населения в условиях чумы была характерна одна и та же практика - бежать от чумы, тем самым способствуя распространению этого заболевания.

Для борьбы с чумой было принято не только применять частое купание, но и окуривать товары и одежду на кострах, это приводило к обеззараживанию вещей. Так или иначе, но чума пошла на убыль, а уже в марте 1823 г. эпидемиологическая обстановка была в норме - чума не фиксировалась ни в Анапе, ни в черкесских аулах (ГАКК. Ф. 324. Оп. 1. Д. 34. Л. 13-14).

В начале XIX века действовал Карантинный устав, согласно которому велось карантинное очищение лиц и товаров, пересекавших государственную границу. Устав распространялся не только 
на торговцев и путешествующих, но и на части русской армии, которые решали те или иные задачи на территории Закубани (ГАКК. Ф. 324. Оп. 1. Д. 34. Л. 7об.-16об.).

О важности наблюдения за санитарной обстановкой в регионе свидетельствовал и тот факт, что переписка по этому вопросу доходила до самого верха в иерархической системе Российской империи. В 1830 г. в связи с появившимися случаями заболевания чумой за Владикавказом, в селениях Казбек и Гургетт, был опубликован высочайший указ императора Николая I о мерах предосторожности на всей государственной границе. В результате Екатеринодарская карантинная контора рекомендовала служащим карантинных застав при переговорах с горцами быть с ними на как можно дальнем расстоянии и при том «разведывать, не появилась ли или не появится ли помянутая опасная болезнь где-либо за Кубанью близ границ наших» (ГАКК. Ф. 687. Оп. 1. Д. 31. Л. 1-2).

В январе 1830 г. ограничительные меры коснулись и закубанских жителей, которые проживали на русской территории в Гривенском черкесском ауле: на время чумы им разрешено было общаться с закубанцами только по личному распоряжению войскового атамана Черноморского казачьего войска (ГАКК. Ф. 329. ОП. 1. Д. 9. Л. 8).

В 1835 г. на Кавказе снова была обнаружена чума. В результате по распоряжению начальника Кавказской области были приняты меры предосторожности, которые вновь остановили меновую торговлю с горцами. Так, смотритель Усть-Лабинского менового двора 1 марта 1835 г. доносил коменданту Усть-Лабинской крепости, что «получив ныне предписание от Екатеринодарской карантинной конторы, что по открывшемуся сомнению о неблагополучном состоянии от чумной заразы в горах, господин начальник Кавказской области впредь до благополучного времени мену с горцами на меновых дворах даже на казенную соль воспретил. О чем, уведомляя ваше высокоблагородие, честь имею присовокупить, что я по случаю сему доставки дров для здешнего военно-временного госпиталя мены производить на оные не могу и оных у меня тем более в наличности нисколько не состоит» (ГАКК. Ф. 687. Оп. 1. Д. 79. Л. 1-10б.).

В октябре 1836 г. стало известно о чуме у убыхов и шапсугов. Так, 29 октября от закубанского армянина Мелкона Хачедурова, прибывшего на Екатеринодарский меновый двор, стало известно, что в черкесских владениях - убыхском на речке Шаше и Вае и шапсугском на реке Недожепсухо - два месяца назад началась чумная болезнь и что в продолжении этого времени умерло от этой болезни скоропостижно девять семейств, но, сколько человек, ему не известно. Чума и в настоящее время продолжается в этих селениях, а наиболее сильно на реке Недожепсухо, которая находилась на расстоянии в 70 верст от Екатеринодара. О существовании этой болезни на меновом дворе подтвердили и другие черкесы. В результате вновь были приняты строгие меры, меновая торговля прекращена (ГАКК. Ф. 249. Оп. 1. Д. 1495. Л. 11).

Эта же информация была донесена смотрителем Усть-Лабинского менового двора в рапорте на имя главного смотрителя меновых дворов Кавказской линии статского советника Дудышкина от 21 октября 1836 г. В результате и на этом меновом дворе обмен товарами с горцами был прекращен (ГАКК. Ф. 687. ОП. 1. Д. 105. Л. 1-10б.).

Тем временем чума быстро распространилась по черкесской территории. И уже в ноябре 1836 г. этот вопрос стал обсуждаться в Министерстве внутренних дел Российской империи. 24 ноября чиновники ведомства в письме к наказному атаману Черноморского войска констатировали: «Известия о существовании чумной заразы между горскими народами подтверждаются. Военный министр от 22 сего месяца уведомил меня, что по сведениям, доставленным генерал-лейтенантом Вельяминовым, чумная зараза, оказавшаяся на восточном берегу Черного моря, перенесена чрез хребет Кавказских гор в землю натухайцев. Из прежних отношений Вашего Превосходительства мне известно, что вы уже изволили распорядиться на счет принятия надлежащих мер предосторожности, против распространения чумной болезни и внесения оной чрез Карантинную линию, но, при предстоящем ныне возвращении действующего за Кубанью отряда войск, я обязываюсь опять сообщить Вам, Милостивый Государь, о необходимости усугубить меры предосторожности по всей Карантинной линии. В особенности нужным считаю строжайше подтвердить всем Карантинным Чиновникам, чтобы они неослабно исполнили все предписанные в карантинном Уставе правила, чтобы никто из приходящих и из приезжающих из-за Кубани не был пропускаем без выдержания предписанного законом срока обсервации; чтобы все вещи, заразе подверженные, очищаемы были, сообразно их роду и качеству, приличными способами в Карантинном Уставе изложенными, а животные обмываемы, как в том же Уставе предписано. От строгого и точного исполнения сих правил зависит безопасность края, на счет вторжения чумной заразы. Касательно возвращающихся из-за Кубани войск Карантинные меры должны быть также соблюдаемы со всею возможною строгостию» (ГАКК. Ф. 249. Оп. 1. Д. 1495. Л. 124).

Нужно также отметить, что фиксировались случаи поступления недостоверной информации о вспышке чумы в регионе. Так, 30 октября 1842 г. сотник Котляров донес на Усть-Лабинский меновый двор, что в мирном ауле князя Дженгирея Карканукова свирепствует заразная болезнь, от которой в короткое время умерло более 30 человек (ГАКК. Ф. 687. Оп. 1. Д. 186. Л. 1-10б.). После перепроверки этой информации было выяснено, что вспышка являлась лишь слухом. В результате работа менового двора не была остановлена, а продолжалась в штатном режиме. 
Так или иначе, но, стремясь защитить свою территорию от занесения чумы, русская администрация на границе занималась мониторингом ситуации в Черкесии, сбором и перепроверкой информации о возникновении чумных очагов, а также созданием карантинов и разработкой методов очищения товаров и скота от инфекции. Все это в целом приводило к тому, что методику борьбы с чумой перенимало и горское население, что создавало условия для более эффективной борьбы с чумой.

\section{5. Заключение}

Таким образом, вспышки заболевания чумой на территории Черкесии не были редкостью: они фиксировались в 1796 г., 1801-1802 гг., 1820 г., 1822-1823 гг., 1830 г., а также 1835-1836 гг. Как в Грузии, так и в Черкесии защитной реакцией населения на вспышку чумы было бегство из района эпидемии, чем оно способствовало распространению чумы на новые, еще не охваченные ею районы. Минимизировать риск заражения чумой региона в Черкесии можно было только карантинными мероприятиями на Черноморском побережье для всех приезжающих. Однако это на данном этапе развития черкесского общества было невозможно сделать ввиду его децентрализации, а также высокой степени зависимости от торговли с Османской империей.

\section{Литература}

Котенев и др., 2016 - Котенев Е.С., Дубянский В.М., Волынкина А.С., Зайцев А.А., Куличенко A.Н., Кравцова С.Л. История эпидемий чумы на Северном Кавказе и современный эпидемический потенциал природных очагов чумы // Медицинский вестник Северного Кавказа. 2016. T. 11. № 4. С. 612-616.

Туренко, 1887 -Туренко А.М. Исторические записки о войске Черноморском. Киев, 1887.

Хайдаров, 2017 -Хайдаров Т.Ф. Эпидемии чумы в Каспийском регионе во второй половине XIV - начале XV вв. // Золотоордынская циивилизация. 2017. № 10. С. 304-309.

Cherkasov et al., 2017 - Cherkasov A.A., Smigel M., Bratanovskii S., Valleau A. The losses of the Russian army during the Russian-Persian war of 1826-1828: The historical-statistical study // Bylye Gody. 2017. 46(4): 1315-1321.

Cherkasov et al., 2017a - Cherkasov A.A., Bratanovskii S.N., Valleau A. The losses of the Russian army in transcaucasia during the Russo-Turkish war (1828-1829): The historical-statistical study // Rusin. 2017. № 50(4). C. 38-60.

Ermachkov et al., 2017 - Ermachkov I.A., Koroleva L.A., Svechnikova N.V. The Sanitary-epidemiological State of the Russian Troops in the Caucasus in 1797-1801 // Bylye Gody. 2018. 44(2): 428-437.

Ermachkov et al., 2017a - Ermachkov I.A., Koroleva L.A., Svechnikova N.V., Gut J. The Traditional Medicine in the Caucasus and the Activities of the Georgian Medical Board (1801-1804 years) // Bylye Gody. 2018. 45(3): 836-846.

Ermachkov et al., 2017b - Ermachkov I.A., Koroleva L.A., Svechnikova N.V., Gut J. Military-Sanitary Affairs in the Caucasus in 1803-1808 years: the Characteristic Peculiarities // Bylye Gody. 2018. 46(4): 1252-1260.

Ermachkov et al., 2018 - Ermachkov I.A., Koroleva L.A., Svechnikova N.V., Gut J. The Plague in the Caucasus in 1801-1815 years: Part I // Bylye Gody. 2018. 47(1): 120-129.

Ermachkov et al., 2018a - Ermachkov I.A., Koroleva L.A., Svechnikova N.V., Gut J. The Plague in the Caucasus in 1801-1815 years: Part II // Bylye Gody. 2018. 48(2): 558-569.

Ermachkov et al., 2018b - Ermachkov I.A., Koroleva L.A., Svechnikova N.V., Gut J. General Ermolov and His Role in the Evolution of Public Health Service in the Caucasus // Bylye Gody. 2018. 49(3): 1037-1045.

Ermachkov et al., 2018c - Ermachkov I.A., Koroleva L.A., Svechnikova N.V., Gut J. Sanitary Provision in the Caucasus during the Russian-Persian War of 1826-1828 // Bylye Gody. 2018. 50(4): 1566-1574.

\section{References}

Cherkasov et al., 2017 - Cherkasov, A.A., Smigel, M., Bratanovskii, S., Valleau, A. (2017). The losses of the Russian army during the Russian-Persian war of 1826-1828: The historical-statistical study. Bylye Gody. 46(4): 1315-1321.

Cherkasov et al., 2017a - Cherkasov, A.A., Bratanovskii, S.N., Valleau, A. (2017). The losses of the Russian army in transcaucasia during the Russo-Turkish war (1828-1829): The historical-statistical study. Rusin. 50(4): 38-60.

Ermachkov et al., 2017 - Ermachkov, I.A., Koroleva, L.A., Svechnikova, N.V. (2017). The Sanitaryepidemiological State of the Russian Troops in the Caucasus in 1797-1801. Bylye Gody. 44(2): $428-437$.

Ermachkov et al., 2017a - Ermachkov, I.A., Koroleva, L.A., Svechnikova, N.V., Gut, J. (2017). The Traditional Medicine in the Caucasus and the Activities of the Georgian Medical Board (18011804 years). Bylye Gody. 45(3): 836-846.

Ermachkov et al., 2017b - Ermachkov, I.A., Koroleva, L.A., Svechnikova, N.V., Gut, J. (2017). Military-Sanitary Affairs in the Caucasus in 1803-1808 years: the Characteristic Peculiarities. Bylye Gody. 46(4): 1252-1260. 
Ermachkov et al., 2018 - Ermachkov, I.A., Koroleva, L.A., Svechnikova, N.V., Gut, J. (2018). The Plague in the Caucasus in 1801-1815 years: Part I. Bylye Gody . 47(1): 120-129.

Ermachkov et al., 2018a - Ermachkov, I.A., Koroleva, L.A., Svechnikova, N.V., Gut, J. (2018). The Plague in the Caucasus in 1801-1815 years: Part II. Bylye Gody. 48(2): 558-569.

Ermachkov et al., 2018b - Ermachkov, I.A., Koroleva, L.A., Svechnikova, N.V., Gut, J. (2018). General Ermolov and His Role in the Evolution of Public Health Service in the Caucasus. Bylye Gody. 49(3): 1037-1045.

Ermachkov et al., 2018c - Ermachkov, I.A., Koroleva, L.A., Svechnikova, N.V., Gut, J. (2018). Sanitary Provision in the Caucasus during the Russian-Persian War of 1826-1828. Bylye Gody. 50(4): 1566-1574.

Khaidarov, 2017 - Khaidarov, T.F. (2017). Epidemii chumy v Kaspiiskom regione vo vtoroi polovine XIV - nachale XV vv. [Plague epidemics in the Caspian region in the second half of XIV - early XV centuries]. Zolotoordynskaya tsivilizatsiya. 10: 304-309. [in Russian]

Kotenev i dr., 2016 - Kotenev, E.S., Dubyanskii, V.M., Volynkina, A.S., Zaitsev, A.A., Kulichenko, A.N., Kravtsova, S.L. (2016). Istoriya epidemii chumy na Severnom Kavkaze i sovremennyi epidemicheskii potentsial prirodnykh ochagov chumy [The history of plague epidemics in the North Caucasus and the modern epidemic potential of natural foci of plague]. Meditsinskii vestnik Severnogo Kavkaza. 11(4): 612-616. [in Russian]

Turenko, 1887 - Turenko, A.M. (1887). Istoricheskie zapiski o voiske Chernomorskom [Historical notes on the army of the Black Sea]. Kiev. [in Russian]

\section{К вопросу о распространении чумы в Черкесии в первой половине XIX века}

Тимур Альбертович Магсумов a, b , c, *, Теймур Эльдарович Зульфугарзаде ${ }^{\mathrm{d}}$ Михаил Борисович Колотков ${ }^{e}$, Сергей Борисович Зинковский ${ }^{\mathrm{f}}$

а Черкас глобальный университет, Вашингтон, США

b Волгоградский государственный университет, Волгоград, Российская Федерация

c Набережночелнинский государственный педагогический университет, Набережные Челны, Российская Федерация

$\mathrm{d}$ Российский экономический университет имени Г.В. Плеханова, Москва, Российская Федерация

е Санкт-Петербургский политехнический университет Петра Великого, Санкт-Петербург,

Российская Федерация

f Российский университет дружбы народов, Москва, Российская Федерация

Аннотация. В работе рассматривается санитарно-эпидемиологическое состояние Черкесии в первой половине XIX века. Уделено внимание причинам возникновения очагов чумы в регионе, а также факторам, способствующим ее распространению.

В качестве источников привлечены документы государственного архива Краснодарского края (Краснодар, Российская Федерация), которые впервые введены в научный оборот. В работе были использованы документы 5 фондов: 249 «Канцелярия наказного (войскового) атамана Кубанского казачьего войска, г. Екатеринодар Кубанской области, 1787-1917 гг.»; 250 «Войсковая канцелярия Черноморского казачьего войска, г. Екатеринодар, 1794-1842 гг.»; 324 «Екатеринодарский частный карантин, г. Екатеринодар, 1801-1861 гг.»; 329 «Екатеринодарский меновой двор Черноморского казачьего войска, г. Екатеринодар, 1830-1846 гг.»; 687 «Усть-Лабинский меновый двор главного попечителя кавказских меновых сношений с горцами».

Важное значение в работе имеет принцип историзма, благодаря которому были рассмотрены вспышки чума на территории Черкесии в контексте сложившейся исторической обстановки на всем Кавказе. Кроме того, в ходе работы применялись общенаучные методы: логический, классификационный, метод факторного анализа и др., а также такие специальные методы исследования, как сравнительный, статистический и типологический.

В заключении авторы отмечают, что вспышки заболевания чумой на территории Черкесии не были редкостью, они фиксировались в 1796 г., 1801-1802 гг., 1820 г., 1822-1823 гг., 1830 г., а также 1835-1836 гг. Как в Грузии, так и в Черкесии защитной реакцией населения на вспышку чумы было бегство из района эпидемии, чем оно способствовало распространению чумы на новые, еще не охваченные ею районы. Минимизировать риск заражения чумой Черкесии можно было только карантинными мероприятиями на Черноморском побережье для всех приезжающих. Однако это на данном этапе развития черкесского общества было невозможно сделать ввиду его децентрализации, а также высокой степени зависимости от торговли с Османской империей.

Ключевые слова: чума, Черкесия, Кавказ, первая половина XIX века, Российская империя, карантины, меновые дворы, Османская империя, горцы.

\footnotetext{
${ }^{*}$ Корреспондирующий автор

Адреса электронной почты: nabonid1@yandex.ru (Т.А. Магсумов) 